\title{
BMJ Open Impact of hepatitis C virus infection on long-term mortality after acute myocardial infarction: a nationwide population-based, propensity-matched cohort study in Taiwan
}

\author{
Shu-Hung Kuo, ${ }^{1}$ Wang-Ting Hung, ${ }^{1}$ Pei-Ling Tang, ${ }^{1}$ Wei-Chun Huang, ${ }^{1,2,3}$ \\ Jin-Shiou Yang, ${ }^{2}$ Hsiao-Chin Lin, ${ }^{1}$ Guang-Yuan Mar, ${ }^{1}$ Hong-Tai Chang, ${ }^{1}$ \\ Chun-Peng $\mathrm{Liu}^{1,3}$
}

To cite: Kuo S-H, Hung W-T, Tang P-L, et al. Impact of hepatitis $C$ virus infection on long-term mortality after acute myocardial infarction: a nationwide population-based, propensity-matched cohort study in Taiwan. BMJ Open 2018;8:e017412. doi:10.1136/ bmjopen-2017-017412

- Prepublication history and additional material for this paper are available online. To view these files, please visit the journal online (http://dx.doi org/10.1136/bmjopen-2017017412).

W-CH and C-PL contributed equally,

S-HK and W-TH contributed equally.

Received 21 April 2017 Accepted 6 December 2017

Check for updates

${ }^{1}$ Critical Care Center and Cardiovascular Medical Center, Kaohsiung Veterans General Hospital, Kaohsiung, Taiwan ${ }^{2}$ Department of Physical Therapy, Fooyin University, Kaohsiung, Taiwan

${ }^{3}$ School of Medicine, National Yang-Ming University, Taipei, Taiwan

Correspondence to Professor Wei-Chun Huang; wchuanglulu@gmail.com

\section{ABSTRACT}

Introduction The influence of hepatitis $\mathrm{C}$ virus $(\mathrm{HCV})$ infection on long-term outcomes of patients with acute myocardial infarction (AMI) is unclear. Therefore, this study aimed to analyse the impact of HCV infection on 12-year mortality rates after AMl using data from the Taiwan National Health Insurance Research Database (NHIRD). Methods NHIRD data for approximately 23000000 patients between January 2000 and December 2012 were analysed. A total of 186112 cases of first AMI admission were identified. A total of 4659 patients with HCV infection not receiving interferon therapy were enrolled and divided into those with $(n=107)$ or without $(n=4552)$ cirrhosis. Using one-to-one matching, 4552 matched controls were included in the final analysis.

Results The 12-year mortality rate was significantly higher in patients with AMI with HCV infection and cirrhosis than in those with HCV infection but without cirrhosis $(P<0.0001)$ or controls $(P<0.0001)$. Patients with HCV infection but without cirrhosis had significantly higher long-term mortality rates than the matched controls $(\mathrm{P}<0.0001)$. The HR for mortality was higher in patients with HCV infection (HR 1.12; 95\% Cl 1.06 to 1.18). HCV influenced outcomes among the subgroups of patients who were male (HR 1.15) and those who had hypertension (HR 1.14).

Conclusions HCV infection influenced the 12-year mortality rates of patients with AMI, especially those who were male and those who had hypertension. Cirrhosis further increased the long-term mortality rates of patients with AMI with HCV infection.

\section{INTRODUCTION}

Acute myocardial infarction (AMI), one of the leading causes of death among men and women in Taiwan and worldwide, is now becoming increasingly more common in developed countries. ${ }^{1}$ The coronary arteries of patients with AMI have lipid-rich cores after atherosclerosis plaque rupture that induce the formation of unstable platelet aggregates

\section{Strengths and limitations of this study}

- This cohort study was based on Taiwan National Health Insurance Research Database (NHIRD) data, a representative sample of approximately 23000000 subjects from $93 \%$ of the medical institutions of Taiwan over the past 12 years.

- The diagnosis of the population with acute myocardial infarction might not be confirmed owing to the lack of information on the burden of atherosclerosis assessed.

- This cohort study based on NHIRD data might underestimate the hepatitis C virus infected population.

- The database does not include data on family history; actual cause of death; body weight; body height; smoking history; or lipid, viral load and glucose levels, all of which might be potential confounding factors.

- The distinct cause-effect correlation remains vague and is pending further study for clarification.

following an intermittent reduction in coronary flow and distal embolisation. ${ }^{23}$ Despite advances in revascularisation and medications, AMI can still trigger lethal arrhythmia, haemodynamic instability or death. Therefore, assessing the risk factors of clinical outcomes after AMI remains an important research topic. ${ }^{4-7}$ Infection has been hypothesised as a contributing risk factor of coronary artery disease (CAD) ${ }^{8}{ }^{9}$ Several direct and indirect mechanisms have been proposed to explain the association between infectious agents and coronary heart disease. ${ }^{9-11}$

An estimated 2\%-3\% of the global population is infected with the hepatitis $\mathrm{C}$ virus (HCV). ${ }^{12} \mathrm{HCV}$ infection was proposed to be associated with endothelial dysfunction, ${ }^{13}$ atherosclerosis, ${ }^{10}{ }^{14-16} \mathrm{CAD},{ }^{17-19}$ carotid 
artery disease ${ }^{20}$ and stroke. ${ }^{21}{ }^{22}$ However, the association between HCV infection and CAD remains controversial. ${ }^{23-27}$ Previous studies showed an association between the HCV core protein and carotid atherosclerosis ${ }^{18}$ as well as between HCV seropositivity and CAD. ${ }^{10}{ }^{28}{ }^{29}$ However, in a study of active-duty military personnel with a high prevalence of HCV infection, no association was found between HCV seropositivity and AMI. ${ }^{9}$ Additionally, other studies reported no association between HCV infection and $\mathrm{CAD},{ }^{30}$ carotid plaques ${ }^{31}$ or the risk of incident myocardial infarction. ${ }^{32} 33$ A recent study showed that patients with HCV infection had less obstructive CAD on coronary angiography. ${ }^{34}$ Furthermore, the influence of HCV infection on the long-term outcomes of patients after AMI is unclear.

The present study aimed to analyse the impact of HCV infection on 12-year mortality after AMI using data from the Taiwan National Health Insurance Research Database (NHIRD).

\section{MATERIAL AND METHODS}

The National Health Insurance (NHI) programme in Taiwan has financed the healthcare of more than $99 \%$ of its residents since 1995. NHIRD includes detailed information from the medical records of patients admitted to hospitals, including their age, sex, diagnosis, prescriptions, interventions and relevant survival data.

All patients who were admitted to hospitals with the main diagnosis of AMI (International Classification of Diseases, ninth edition, Clinical Modification (ICD-9-CM) codes 410-410.92) between January 2000 and December 2012 were identified from NHIRD, which includes data for approximately 23000000 patients. Among these patients, those with a history of admission for AMI, whose sex was undetermined or who were $<18$ years of age were excluded, and a total of 186112 unique cases of AMI were identified (online supplementary figure).

Of the 186112 patients, 4666 with HCV infection (ICD-9-CM codes V02.62, 070.51 and 070.54) were identified. Among the remaining 181446 patients, those with a history of hepatitis (ICD-9-CM codes V02.61, 070.30, 070.32 and 571.1) or other liver-associated diseases (ICD-9-CM codes 155, 070, 570, 571, 572, 573, 197.7, 230.8, 235.3, 789.1 and V02.6) were excluded, leaving 112896 AMI controls (online supplementary figure).

Of the 4666 patients with AMI with HCV infection, those who had ever received interferon therapy were excluded to minimise the variables. Therefore, a total of 4659 patients with HCV infection were enrolled and further divided into those with $(\mathrm{n}=107)$ and those without $(n=4552)$ liver cirrhosis. To minimise baseline differences between the AMI cohort with HCV infection but without liver cirrhosis and the control group, a propensity score-matching technique was used. One-to-one matching was performed using the following variables: sex, age, hypertension (IDC-9-CM codes 401-405), dyslipidaemia (IDC-9-CM code 272), peripheral vascular disease (ICD-9-CM codes 443.9, $441,441.9,785.4$ and V43.4 or procedure code 38.48 ), diabetes mellitus (ICD-9-CM code 250), heart failure (ICD-9-CM code 428), previous stroke (ICD-9-CM codes 430-437 and A290-A294), end-stage renal disease (ESRD; ICD-9-CM code 585), chronic obstructive pulmonary disease (ICD-9-CM codes 491, 492 and 496 ), and percutaneous coronary intervention (PCI, CD-9-CM procedure codes 36.0, 36.01, 36.02, 36.05, 36.06 and 36.09). The data from 4552 patients with AMI with HCV infection but without liver cirrhosis and from 4552 matched controls were included in the final analysis (online supplementary figure).

For the outcome analysis, survival was defined as the time interval from the hospital admission date to the NHI coverage end date. Since the NHI premium is paid monthly, coverage can easily be discontinued at the time of death. Thus, the end date of NHI coverage is a valid proxy for mortality, which had a maximum error of 1 month. ${ }^{35-39}$

\section{Statistical analysis}

SAS software (V.9.4; SAS Institute, Cary, North Carolina, USA) was used to extract and analyse the data. Descriptive statistics were calculated for all variables, with categorical data reported as percentile values and continuous data reported as mean and SD. The paired $t$-test was used to compare continuous variables and the $\chi^{2}$ test was used to compare categorical variables among the groups. HRs, CIs and P values from Cox proportional hazards regression models are presented. Kaplan-Meier cumulative survival curves were constructed to compare survival among the groups. P values $<0.05$ were considered statistically significant.

\section{RESULTS}

\section{Characteristics of the study group}

The characteristics of the 4552 patients with HCV infection but without cirrhosis and the 4552 patients in the control group are presented in table 1 . The primary demographic variables of age, male to female distribution and comorbidities were comparable among the groups. Additionally, the medications used were comparable among the groups except for antiplatelet medications $(\mathrm{P}=0.0005)$ and statins $(\mathrm{P}=0.0323)$, which were used more often in the control group than in the HCV-infected group (table 1). The proportion of patients who underwent PCI was comparable between the HCV-infected without liver cirrhosis group $(42.95 \%)$ and the control group (43.23\%; $\mathrm{P}=0.7832)$, independent of the sex or age subgroup (table 1 ).

Compared with group 1 (matched control group) and group 2 (patients with HCV infection without cirrhosis group), the 107 patients with AMI with HCV infection and liver cirrhosis had a lower male ratio, lower prevalence of dyslipidaemia and higher prevalence of diabetes 
Table 1 Characteristics of all patients with first hospitalised AMI with and without HCV infection in this propensity scorematched case control study

\begin{tabular}{|c|c|c|c|c|c|c|}
\hline \multirow[b]{2}{*}{ Characteristics } & \multirow{2}{*}{$\begin{array}{l}\begin{array}{l}\text { AMI cohort } \\
\text { without HCV }\end{array} \\
\mathrm{n}=4552 \\
\text { Group } 1\end{array}$} & \multirow{2}{*}{$\begin{array}{l}\text { AMI cohort with } \\
\text { HCV but not liver } \\
\text { cirrhosis } \\
\mathrm{n}=4552 \\
\text { Group } 2\end{array}$} & \multirow{2}{*}{$\begin{array}{l}\text { AMI cohort with } \\
\text { HCV and liver } \\
\text { cirrhosis } \\
\text { n=107 } \\
\text { Group } 3\end{array}$} & \multicolumn{3}{|l|}{$P$ values } \\
\hline & & & & $\begin{array}{l}\text { Group } 1 \\
\text { versus } \\
\text { group } 2\end{array}$ & $\begin{array}{l}\text { Group 3 } \\
\text { versus } \\
\text { group } 2\end{array}$ & $\begin{array}{l}\text { Group } 3 \\
\text { versus } \\
\text { group } 1\end{array}$ \\
\hline Age $<65$ years & 1538 (33.79\%) & 1574 (34.58\%) & 41 (38.32\%) & 0.4264 & 0.4217 & 0.3278 \\
\hline Male participants & $2812(61.78 \%)$ & $2826(62.08 \%)$ & $55(51.4 \%)$ & 0.7625 & 0.0246 & 0.0293 \\
\hline \multicolumn{7}{|l|}{ Comorbidity } \\
\hline Hypertension & $3214(70.61 \%)$ & 3197 (70.23\%) & $66(61.68 \%)$ & 0.6963 & 0.0563 & 0.0456 \\
\hline Dyslipidaemia & $1680(36.91 \%)$ & $1703(37.41 \%)$ & $20(18.69 \%)$ & 0.6179 & $<0.0001$ & 0.0001 \\
\hline Diabetes mellitus & 2217 (48.7\%) & $2163(47.52 \%)$ & $70(65.42 \%)$ & 0.2573 & 0.0002 & 0.0006 \\
\hline Peripheral vascular disease & 220 (4.83\%) & $246(5.4 \%)$ & $3(2.8 \%)$ & 0.2163 & 0.2371 & 0.3311 \\
\hline Heart failure & $1305(28.67 \%)$ & $1339(29.42 \%)$ & 31 (28.97\%) & 0.4325 & 0.9207 & 0.9453 \\
\hline End-stage renal disease & $681(14.96 \%)$ & $697(15.31 \%)$ & $13(12.15 \%)$ & 0.6399 & 0.3683 & 0.4195 \\
\hline Previous stroke & $1219(26.78 \%)$ & $1226(26.93 \%)$ & $25(23.36 \%)$ & 0.8685 & 0.4103 & 0.4300 \\
\hline $\begin{array}{l}\text { Chronic obstructive } \\
\text { pulmonary disease }\end{array}$ & 745 (16.37\%) & 777 (17.07\%) & $14(13.08 \%)$ & 0.3688 & 0.2778 & 0.3635 \\
\hline \multicolumn{7}{|l|}{ Medication } \\
\hline Any antiplatelet & $3821(83.94 \%)$ & $3695(81.17 \%)$ & $68(63.55 \%)$ & 0.0005 & $<0.0001$ & $<0.0001$ \\
\hline ACEI or ARB & $2571(56.48 \%)$ & $2523(55.43 \%)$ & $32(29.91 \%)$ & 0.3109 & $<0.0001$ & $<0.0001$ \\
\hline Statin & $1288(28.3 \%)$ & $1197(26.3 \%)$ & $13(12.15 \%)$ & 0.0323 & 0.0010 & 0.0002 \\
\hline$\beta$-blocker & $2191(48.13 \%)$ & $2156(47.36 \%)$ & $36(33.64 \%)$ & 0.4627 & 0.0049 & 0.003 \\
\hline Calcium channel blocker & $1615(35.48 \%)$ & $1631(35.83 \%)$ & $26(24.3 \%)$ & 0.7263 & 0.0138 & 0.0167 \\
\hline Heparin & $2579(56.66 \%)$ & 2548 (55.98\%) & $40(37.38 \%)$ & 0.5124 & 0.0001 & $<0.0001$ \\
\hline $\begin{array}{l}\text { Low molecular weight } \\
\text { heparin }\end{array}$ & $1173(25.77 \%)$ & $1151(25.29 \%)$ & $20(18.69 \%)$ & 0.5969 & 0.1201 & 0.0973 \\
\hline Dopamine & $824(18.1 \%)$ & 762 (16.74\%) & $29(27.1 \%)$ & 0.0867 & 0.0048 & 0.0173 \\
\hline Epinephrine & $227(4.99 \%)$ & $224(4.92 \%)$ & $8(7.48 \%)$ & 0.8848 & 0.2296 & 0.2447 \\
\hline Norepinephrine & $601(13.2 \%)$ & $596(13.09 \%)$ & $19(17.76 \%)$ & 0.8768 & 0.1589 & 0.1704 \\
\hline Atropine & $161(3.54 \%)$ & $146(3.21 \%)$ & $5(4.67 \%)$ & 0.3838 & 0.3975 & 0.4328 \\
\hline Nitrate & 3509 (77.09\%) & 3508 (77.07\%) & 72 (67.29\%) & 0.9801 & 0.0178 & 0.0175 \\
\hline Nicorandil & $381(8.37 \%)$ & $434(9.53 \%)$ & $9(8.41 \%)$ & 0.0517 & 0.6955 & 0.9878 \\
\hline $\mathrm{PCl}$ & $1968(43.23 \%)$ & 1955 (42.95\%) & $25(23.36 \%)$ & 0.7832 & $<0.0001$ & $<0.0001$ \\
\hline $\mathrm{PCl}$ ratio in male patients & $1377(48.97 \%)$ & $1372(48.55 \%)$ & $15(27.27 \%)$ & 0.7527 & 0.0018 & 0.0014 \\
\hline $\mathrm{PCl}$ ratio in female patients & 591 (33.97\%) & $583(33.78 \%)$ & $10(19.23 \%)$ & 0.9069 & 0.0284 & 0.0266 \\
\hline $\begin{array}{l}\mathrm{PCl} \text { ratio in patients } \\
\text { aged }<65 \text { years }\end{array}$ & $840(54.62 \%)$ & 842 (53.49\%) & $11(26.83 \%)$ & 0.5300 & 0.0007 & 0.0004 \\
\hline $\mathrm{PCl}$ ratio, age $\geq 65$ years & 1128 (37.43\%) & $1113(37.37 \%)$ & $14(21.21 \%)$ & 0.9673 & 0.0072 & 0.007 \\
\hline
\end{tabular}

ACEI, ACE inhibitors; AMI, acute myocardial infarction; ARB, angiotensin receptor blockers; HCV, hepatitis $\mathrm{C}$ virus; $\mathrm{PCl}$, percutaneous coronary intervention.

mellitus. Additionally, the medications used were significantly lower in group 3 than in the other two groups, including antiplatelet, ACE inhibitors (ACEI) or angiotensin receptor blockers (ARBs), statins, $\beta$-blockers, calcium channel blockers, heparin and nitrate. The proportion of patients who underwent PCI was lower in the liver cirrhosis group than in groups 1 and 2.

\section{Outcome analysis}

The 12-year survival rate was significantly lower in patients with AMI with HCV infection and liver cirrhosis than in those with HCV infection but without liver cirrhosis (log-rank, $\mathrm{P}<0.0001)$ and control group (log-rank, $\mathrm{P}<0.0001)$. Furthermore, patients with AMI with HCV infection but without liver cirrhosis had significantly 
lower long-term survival rates than the matched AMI controls (log-rank, $\mathrm{P}<0.0001)$.

In the subgroup analysis, the patients with AMI with liver cirrhosis had lower long-term survival rates than the control group and the patients without cirrhosis regardless of sex, age or PCI status (figure 1). Among the male patients, the mortality rate was lower among the matched controls than among the patients without cirrhosis (log-rank, $\mathrm{P}<0.0001$; figure 1 ), those with younger age (log-rank, $\mathrm{P}<0.0001$; figure 1 ), those who underwent PCI (log-rank, $\mathrm{P}<0.0001$; figure 1$)$ and those who did not undergo PCI (log-rank, $\mathrm{P}=0.0003$; figure 1$)$. However, the 12-year survival rate was comparable between the HCV group without cirrhosis and the AMI control group for female (log-rank, $\mathrm{P}=0.1049$; figure 1 ) and elderly patients ( $\log$-rank, $\mathrm{P}=0.4145$; figure 1 ).

A Cox proportional hazards regression analysis was performed to evaluate the impact of factors including sex, age, comorbidities, PCI, HCV infection, and antiplatelet and statin use on the survival of patients admitted for a first AMI (table 2). Overall, the HR for mortality was high for patients aged $\geq 65$ years (HR 2.22; 95\% CI 2.07 to 2.37) as well as those with diabetes (HR 1.34; 95\% CI 1.27 to 1.42), peripheral vascular disease (HR 1.28; $95 \%$ CI 1.15 to 1.43 ), heart failure (HR $1.27 ; 95 \%$ CI 1.20 to 1.34 ) ESRD (HR 1.78; 95\% CI 1.66 to 1.91 ), previous stroke (HR 1.32; 95\% CI 1.24 to 1.40 ) or chronic obstructive pulmonary disease (HR 1.24; 95\% CI 1.16 to 1.33 ). Conversely, the HR was low for patients who underwent PCI (HR 0.50 ; $95 \%$ CI 0.47 to 0.53 ) and those taking antiplatelet (HR 0.66; 95\% CI 0.61 to 0.70 ) or statin (HR 0.79 ; $95 \%$ CI 0.71 to 0.88 ) medication. Overall, HCV infection was associated with a higher risk for mortality (HR 1.12; $95 \%$ CI 1.06 to 1.18 ).

In further gender subgroup analyses, HCV infection was found to influence the outcomes of male patients but not female patients (HR 1.07; 95\% CI 0.99 to 1.17) (figure 2). $\mathrm{HCV}$ infection also did not impact the outcomes of patients without hypertension (HR 1.06; 95\% CI 0.95 to 1.17), with peripheral vascular disease (HR 1.06; 95\% CI 0.87 to 1.31 ), with cerebrovascular accidents (HR 1.06; 95\% CI 0.97 to 1.17 ) or with chronic obstructive pulmonary disease (HR 1.01; 95\% CI 0.90 to 1.14) (figure 2).

\section{DISCUSSION}

The present study showed that HCV infection influences the 12-year outcome of patients with AMI. To our knowledge, no previous study examined the impact of HCV infection on long-term outcomes after AMI. This study also showed that the survival rate was lower among patients with AMI with HCV infection and liver cirrhosis. Furthermore, HCV infection influenced longterm mortality among the subgroups of patients who were male and had hypertension.

Some studies did not identify an association between HCV seropositivity and myocardial infarction. ${ }^{932}$ However, the previous study population ${ }^{9}$ included young healthy men (age $<50$ years) from the US military, which limited the interpretation and generalisability of the results. Another study reported that HCV infection did not increase the risk of incident myocardial infarction among a large sample of patients from the UK. ${ }^{32}$ The results of the present study are consistent with those of previous studies that linked HCV seropositivity with carotid ${ }^{10} 40$ or coronary atherosclerosis. ${ }^{18}$ Our study included data from NHIRD and evaluated only those patients with first AMI. Additionally, the percentage of elderly patients was comparable between the HCV group (65.42\%) and the control group $(66.21 \%)$. Previous studies mainly investigated the prevalence of coronary events in patients with hepatitis. $^{9}{ }^{32}$ However, our study investigated whether HCV infection influences the outcomes of patients after AMI, which makes it unique.

Tsai et $a l^{19}$ recently showed that the risk of developing acute coronary syndrome was greater in patients with HCV than in those without HCV and that the risk was the highest in middle-aged patients. This previous study focused on the influence of HCV infection on the development of acute coronary syndrome, while our study focused on the influence of HCV infection on the outcomes of patients after AMI. Furthermore, the study by Tsai $e t a l^{19}$ showed that comorbidities such as hypertension, diabetes and dyslipidaemia were more likely to be present in patients with HCV than in those without $\mathrm{HCV}$, which might be attributable to the higher acute coronary syndrome risk in these patients. However, these authors matched only patient age and sex. Using a propensity score-matching technique, our analyses controlled for several established cardiovascular risk factors and other important confounding variables that might influence patient outcomes after AMI, including sex, age, hypertension, dyslipidaemia, peripheral vascular disease, diabetes mellitus, heart failure, previous stroke, ESRD, chronic obstructive pulmonary disease and PCI. Therefore, our study ensured similar baseline characteristics among groups. Our exclusion criteria were also very strict. Patients with hepatitis, liver cirrhosis or other liver diseases were excluded from the HCV infection without cirrhosis and control groups. These exclusions were not mentioned in the study by Tsai $e t a l .{ }^{19}$ Considering these factors, our study accurately analysed the influence of HCV infection on patient outcomes after AMI.

A previous study analysed data from acute care hospitals across the USA in 1999 and 2009 and showed higher inhospital mortality rates in patients with ST elevation myocardial infarction with cirrhosis compared with patients without cirrhosis. ${ }^{41}$ Our study also showed that patients with HCV with cirrhosis had significant higher mortality rates than those without cirrhosis, which was consistent with the study in the USA. ${ }^{41}$ Unlike those studies, our study focused on HCV-related cirrhosis and further showed the impact of cirrhosis on longterm (12-year) outcomes. The higher mortality rates in patients with cirrhosis in this study might have resulted from more cases of diabetes mellitus, lower PCI rates and 
A

B No. at Risk
HCV negative
HCV positive Time (years)

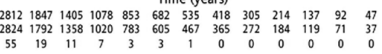

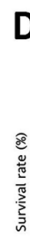

D

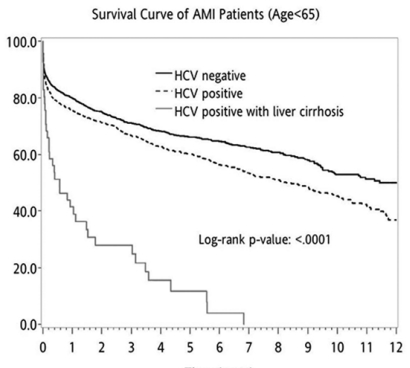

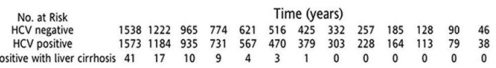

F
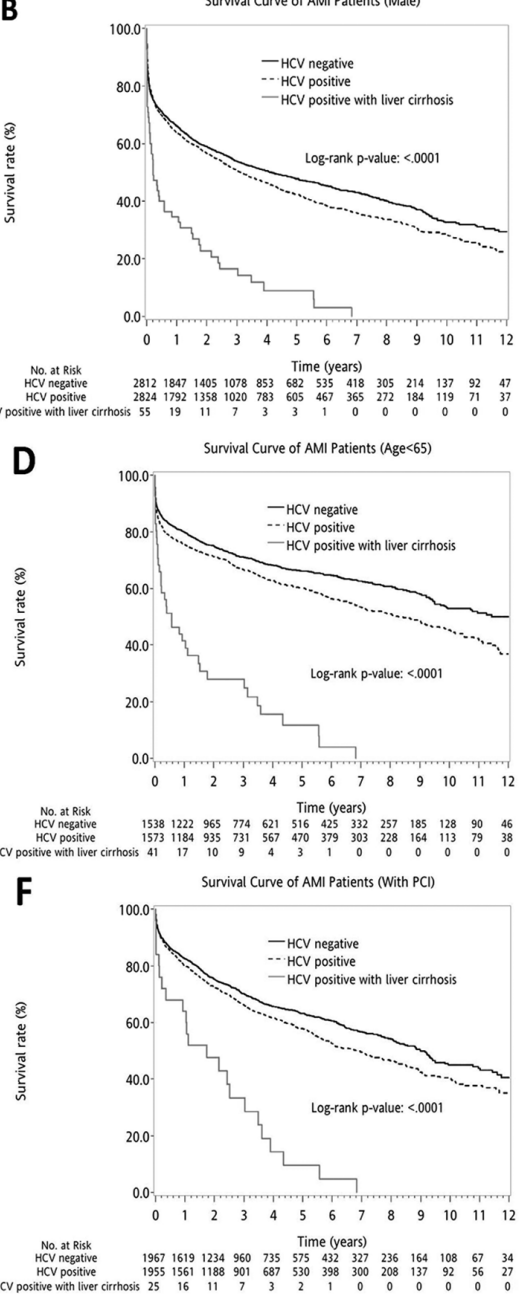

.
Survival Curve of AMI Patients

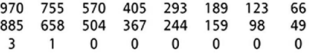

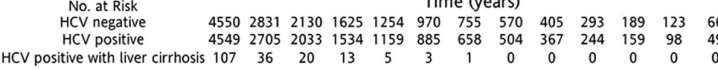

Survival Curve of AMI Patients (Male)

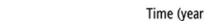

Time (years)

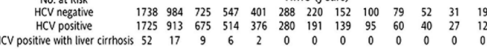

E

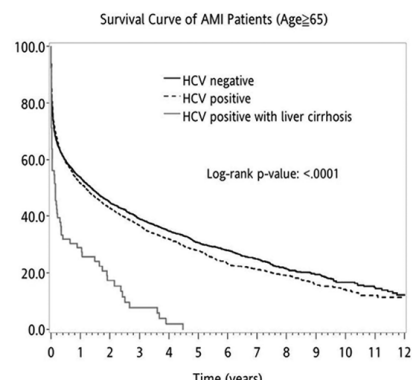

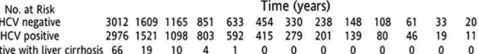

G

Survival Curve of AMI Patients (Without PCI)

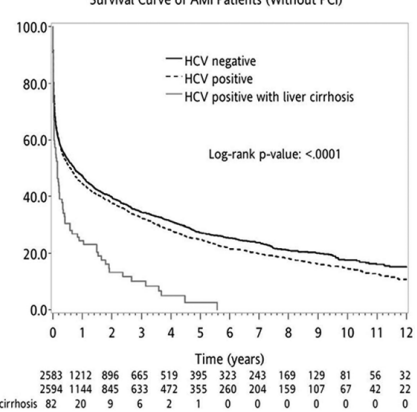

Figure 1 The 12-year Kaplan-Meier survival curves after the first AMI among the control group and the patients with HCV and those without liver cirrhosis (panel A). Panel B shows the survival curve of the male subgroup. Panel $\mathrm{C}$ shows the survival curve of the female subgroup. The patients with liver cirrhosis had lower long-term survival rates than the control group and the male and female patients without cirrhosis. Additionally, the male patients with AMI with HCV but without cirrhosis had higher mortality rates than the matched controls (log-rank, $\mathrm{P}<0.0001$ ). However, there was no difference in long-term mortality rates between female patients in the HCV group and those in the control group (log-rank, $\mathrm{P}=0.10492$ ). Further subgroup analysis by age and $\mathrm{PCl}$ was also demonstrated. Panel $\mathrm{D}$ shows the survival curve of the younger patients (age $<65$ years) subgroup. Panel E shows the survival curve of the elderly patients (age $\geq 65$ years) subgroup. Panel $F$ shows the survival curve of the PCl subgroup. Panel G shows the survival curve of the non-PCl subgroup. The patients with liver cirrhosis had lower long-term survival rates than those in the control group or those without cirrhosis in the younger patient (age <65 years), elderly patient, and $\mathrm{PCl}$ or non- $\mathrm{PCl}$ subgroups. The mortality rate was lower in the matched controls than in patients with HCV but without cirrhosis in the younger (log-rank, $\mathrm{P}<0.0001$ ), $\mathrm{PCl}$ (log-rank, $\mathrm{P}<0.0001$ ) and non- $\mathrm{PCl}$ (log-rank, $\mathrm{P}=0.0003$ ) subgroups. However, the 12-year survival rates were comparable between elderly patients in the HCV and control groups (log-rank, $\mathrm{P}=0.4145$ ). AMI, acute myocardial infarction; $\mathrm{HCV}$, hepatitis $\mathrm{C}$ virus; $\mathrm{PCl}$, percutaneous coronary intervention. 
Table 2 Cox proportional hazards regression analysis in patients with first hospitalised AMI with versus those without HCV infection

\begin{tabular}{|c|c|c|c|}
\hline & All $(n=9104)$ & Male $(n=5652)$ & Female $(n=3452)$ \\
\hline Variable & HR $(95 \% \mathrm{Cl})$ & HR $(95 \% \mathrm{Cl})$ & HR (95\% Cl) \\
\hline Sex (male vs female) & 1.00 (0.95 to 1.06$)$ & - & - \\
\hline Age $(\geqq 65$ vs $<65)$ & $2.22(2.07 \text { to } 2.37)^{\star}$ & $2.43(2.23 \text { to } 2.64)^{\star}$ & $1.88(1.68 \text { to } 2.11)^{*}$ \\
\hline Hypertension (yes vs no) & 0.95 (0.89 to 1.01$)$ & 0.97 (0.89 to 1.05$)$ & $0.92(0.82$ to 1.02$)$ \\
\hline Dyslipidaemia (yes vs no) & $0.85(0.77 \text { to } 0.93)^{*}$ & $0.87(0.77 \text { to } 0.98)^{\star}$ & $0.83(0.72 \text { to } 0.95)^{*}$ \\
\hline Diabetes mellitus (yes vs no) & $1.34(1.27 \text { to } 1.42)^{*}$ & $1.36(1.27 \text { to } 1.47)^{*}$ & $1.30(1.19 \text { to } 1.42)^{*}$ \\
\hline Peripheral vascular disease (yes vs no) & $1.28(1.15 \text { to } 1.43)^{\star}$ & $1.40(1.21 \text { to } 1.61)^{\star}$ & $1.16(0.98$ to 1.38$)$ \\
\hline Heart failure (yes vs no) & $1.27(1.20 \text { to } 1.34)^{*}$ & $1.26(1.17 \text { to } 1.37)^{\star}$ & $1.27(1.17 \text { to } 1.39)^{*}$ \\
\hline End-stage renal disease (yes vs no) & $1.78(1.66 \text { to } 1.91)^{\star}$ & $1.94(1.76 \text { to } 2.14)^{\star}$ & $1.62(1.46 \text { to } 1.80)^{*}$ \\
\hline Previous stroke (yes vs no) & $1.32(1.24 \text { to } 1.40)^{*}$ & $1.32(1.22 \text { to } 1.43)^{\star}$ & $1.33(1.21 \text { to } 1.46)^{*}$ \\
\hline Chronic obstructive pulmonary disease (yes vs no) & $1.24(1.16 \text { to } 1.33)^{*}$ & $1.25(1.15 \text { to } 1.36)^{\star}$ & $1.22(1.08 \text { to } 1.38)^{*}$ \\
\hline Percutaneous coronary intervention (yes vs no) & $0.50(0.47 \text { to } 0.53)^{\star}$ & $0.48(0.44 \text { to } 0.52)^{*}$ & $0.53(0.48 \text { to } 0.59)^{*}$ \\
\hline Antiplatelet drug (yes vs no) & $0.66(0.61 \text { to } 0.70)^{*}$ & $0.67(0.61 \text { to } 0.73)^{\star}$ & $0.64(0.58 \text { to } 0.71)^{*}$ \\
\hline Statin (yes vs no) & $0.79(0.71 \text { to } 0.88)^{*}$ & $0.77(0.67 \text { to } 0.89)^{*}$ & $0.82(0.69 \text { to } 0.96)^{*}$ \\
\hline Hepatitis C (yes vs no) & $1.12(1.06 \text { to } 1.18)^{*}$ & 1.15 (1.07 to 1.24$)^{*}$ & 1.07 (0.99 to 1.17$)$ \\
\hline
\end{tabular}

${ }^{*} \mathrm{P}<0.05$

$\mathrm{AMI}$, acute myocardial infarction; $\mathrm{HCV}$, hepatitis $\mathrm{C}$ virus.

less use of medications, including antiplatelets, ACEIs or ARBs, statins and $\beta$-blockers, and HCV infection itself with or without liver cirrhosis. Other than HCV infection, the PCI intervention and life-saving medication were well-recognised prognostic factors, which influence longterm outcomes through numerous facets, which were also shown in table 2. First, the revascularisation might save cardiac muscle for better residual cardiac function. ${ }^{42}$ Second, prescription of antiplatelets may provide better coronary artery protection. ${ }^{43}$ Third, medication such as ACEI, ARB and $\beta$-blockers can prevent post-AMI cardiac remodelling, and further preserve better cardiac function. ${ }^{44}$ Fourth, all the medications mentioned above can reduce the associated cardiovascular disease risks by controlling metabolic disease. The intergroup differences over lower PCI rates and less use of medications could cause the mortality difference by themselves without related HCV infection. The low PCI rate and use of life-saving medication in patients with cirrhosis could be explained by the following. End-stage liver disease was shown to be associated with thrombocytopenia and coagulopathy predisposing patients to bleeding complications, especially those with oesophageal varices. ${ }^{45} 46$ Furthermore, previous studies have shown that most patients with end-stage liver disease have higher international normalised ratios (INRs), high creatinine values and lower haemoglobin levels. ${ }^{45}$ These patients with cirrhosis might suffer from a higher frequency of periprocedural bleeding, pseudoaneurysm formation and the need for blood products. ${ }^{45} 46$

Several studies have discussed the correlation between sex and outcomes in patients with liver disease. In a southern Sweden 10-year population-based study, female patients with liver cirrhosis had better prognosis than their male counterparts. ${ }^{47}$ In a Centers for Disease Control 2013 surveillance, the HCV-related mortality rate for male patients was approximately 2.6 times that for female patients. ${ }^{48}$ However, no previous studies showed the impact of sex on patients with AMI with HCV. Our study was the first to show that HCV infection influenced long-term mortality in male patients but not in female patients. Previous studies showed that spontaneous resolution was more common in female patients with HCV, ${ }^{49} 50$ which might be part of the reason for the difference.

Interestingly, our study showed that antiplatelets and statins were less frequently used in the HCV group than in the control group, which is consistent with the findings of a recent study. ${ }^{34}$ The low use of antiplatelet medications and statins in patients with HCV could be secondary to physician concerns regarding liver disease and bleeding risk in these patients. ${ }^{33}$ Furthermore, several studies reported that patients with HCV tended to have low cholesterol and low-density lipoprotein levels, which might partially explain the low prescription of statins. ${ }^{1729} 323351-53$ Therefore, to unveil the real weight over each individual factor, Cox proportional hazards regression analysis was used to adjust for possible confounding factors including antiplatelets and statins. After the analysis, HCV infection (HR 1.12; 95\% CI 1.06 to 1.18; table 2) still played a critical role in the long-term mortality of patients with AMI.

The present study has some limitations. First, it was retrospective in design. Therefore, to minimise confounding factors between the HCV and control groups, we used a propensity score-matching technique and found that the characteristics of the controls and the 


\begin{tabular}{|c|c|c|c|c|c|c|}
\hline Subgroup & Hazard Ratio $(95 \% \mathrm{Cl})$ & $\mathbf{N}$ & HCV negative events(? & positive events(\%) & HR $(95 \% \mathrm{Cl})$ & P value \\
\hline All & $\rightarrow-$ & 9104 & $2783(61.14 \%)$ & $2575(56.57 \%)$ & $1.12(1.06-1.18)$ & $<.0001$ \\
\hline \multicolumn{7}{|l|}{ Gender } \\
\hline Female & $\longrightarrow-$ & 3452 & $1148(66.51 \%)$ & 1082(62.69\%) & $1.07(0.99-1.17)$ & 0.0922 \\
\hline Male & $\rightarrow-$ & 5652 & 1635(57.86\%) & $1493(52.83 \%)$ & $1.15(1.07-1.23)$ & 0.0001 \\
\hline \multicolumn{7}{|l|}{ Age } \\
\hline$<65$ & $\longrightarrow$ & 3108 & $655(41.61 \%)$ & $532(34.68 \%)$ & $1.26(1.13-1.42)$ & $<.0001$ \\
\hline$\geqq 65$ & $\rightarrow-$ & 5996 & $2128(71.46 \%)$ & $2043(67.69 \%)$ & $1.08(1.01-1.15)$ & 0.0167 \\
\hline \multicolumn{7}{|l|}{ Hypertension } \\
\hline No & 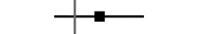 & 2697 & $741(54.69 \%)$ & $691(51.49 \%)$ & $1.06(0.95-1.17)$ & 0.2814 \\
\hline Yes & $\rightarrow-$ & 6407 & 2042(63.87\%) & 1884(58.69\%) & $1.14(1.07-1.21)$ & $<.0001$ \\
\hline \multicolumn{7}{|l|}{ Dyslipidaemia } \\
\hline No & $\rightarrow-$ & 5722 & $1971(69.18 \%)$ & $1871(65.12 \%)$ & $1.10(1.03-1.17)$ & 0.0044 \\
\hline Yes & $\longrightarrow$ & 3382 & $812(47.68 \%)$ & $704(41.93 \%)$ & $1.17(1.05-1.29)$ & 0.0029 \\
\hline \multicolumn{7}{|l|}{ Diabetes } \\
\hline No & $\longrightarrow$ & 4735 & 1357(56.80\%) & $1209(51.53 \%)$ & $1.15(1.06-1.24)$ & 0.0005 \\
\hline Yes & $\rightarrow-$ & 4369 & $1426(65.93 \%)$ & $1366(61.92 \%)$ & $1.09(1.01-1.17)$ & 0.0279 \\
\hline \multicolumn{7}{|c|}{ Peripheral vascular disease } \\
\hline No & $\rightarrow-$ & 8639 & $2586(60.06 \%)$ & $2410(55.62 \%)$ & $1.12(1.06-1.18)$ & $<.0001$ \\
\hline Yes & $\rightarrow$ & 465 & $197(80.08 \%)$ & $165(75.34 \%)$ & $1.06(0.87-1.31)$ & 0.5568 \\
\hline \multicolumn{7}{|l|}{ Heart failure } \\
\hline No & $\rightarrow-$ & 6466 & $1761(54.81 \%)$ & $1661(51.06 \%)$ & $1.11(1.04-1.19)$ & 0.0028 \\
\hline Yes & $\longrightarrow$ & 2638 & $1022(76.33 \%)$ & $914(70.36 \%)$ & $1.13(1.03-1.24)$ & 0.0073 \\
\hline \multicolumn{7}{|c|}{ End stage renal disease } \\
\hline No & $\rightarrow-$ & 7714 & $2237(58.03 \%)$ & $2092(54.21 \%)$ & $1.10(1.04-1.17)$ & 0.0012 \\
\hline Yes & $\longrightarrow$ & 1390 & $546(78.34 \%)$ & $483(69.70 \%)$ & $1.17(1.03-1.32)$ & 0.0135 \\
\hline \multicolumn{7}{|c|}{ Cerebrovascular accidents } \\
\hline No & $\rightarrow-$ & 6664 & 1855(55.77\%) & $1706(51.11 \%)$ & $1.14(1.07-1.22)$ & $<.0001$ \\
\hline Yes & $\rightarrow$ & 2440 & $928(75.69 \%)$ & $869(71.58 \%)$ & $1.06(0.97-1.17)$ & 0.207 \\
\hline \multicolumn{7}{|c|}{ Chronic obstructive pulmonary disease } \\
\hline No & $\rightarrow-$ & 7590 & 2183(57.83\%) & $2003(52.50 \%)$ & $1.15(1.08-1.22)$ & $<.0001$ \\
\hline Yes & $=$ & 1514 & $600(77.22 \%)$ & $572(77.61 \%)$ & $1.01(0.90-1.14)$ & 0.8336 \\
\hline \multicolumn{7}{|l|}{$\mathrm{PCl}$} \\
\hline No & $\rightarrow-$ & 5171 & $1956(75.32 \%)$ & $1837(71.37 \%)$ & $1.09(1.03-1.17)$ & 0.0057 \\
\hline Yes & $\longrightarrow$ & 3933 & $827(42.30 \%)$ & $738(37.31 \%)$ & $1.17(1.06-1.29)$ & 0.002 \\
\hline & \begin{tabular}{l|c|c|c|c} 
& & & 1 \\
0.9 & 1 & 1.1 & 1.3
\end{tabular} & & & & & \\
\hline
\end{tabular}

Figure 2 Forest plot evaluating the impact of HCV in different subgroups of patients after the first AMI. HCV infection influenced the long-term outcomes of subgroups of male patients, those with hypertension and those without peripheral vascular disease, previous stroke or chronic obstructive pulmonary disease. AMI, acute myocardial infarction; HCV, hepatitis C virus; $\mathrm{PCl}$, percutaneous coronary intervention.

patients with HCV but without cirrhosis did not differ. Matching of the groups further supports the results. Second, ICD-9-CM codes for diagnosis of HCV infection were made by positive anti-HCV serology test in NHIRD databases. Previous studies showed the validity of adopting the positive anti-HCV serology result as positive HCV infection was accepted and confirmed. ${ }^{54-56}$ However the database did not provide available confirmatory viral load, which may have slightly underestimated the HCV-infected population. However, the major strength of this study is that the data were obtained from NHIRD, which include data for approximately 23000000 patients over the past 12 years and are representative of the general population in Taiwan. Third, the database used here does not include data on family history; actual cause of death; body weight; body height; smoking history; lipid and viral load, and glucose levels; all are potential confounding factors. Fourth, there was no information on the burden of atherosclerosis assessed using coronary angiography or intracoronary ultrasonography. However, previous studies validated the AMI data in the NHIRD of Taiwan and confirmed the validity of its use for cardiovascular diseases. $^{35} 39$

\section{CONCLUSION}

HCV infection was demonstrated to influence the 12-year mortality of patients after AMI in this study. Additionally, the mortality rate was higher among the patients with HCV infection and liver cirrhosis. Furthermore, HCV 
infection influenced the long-term outcomes of patients after AMI among the subgroups of male patients and those with hypertension. Therefore, physicians should be aware of the impact of HCV infection in patients with AMI when choosing treatment strategies.

Contributors W-CH and G-YM set up the study concept and design. P-LT and H-CL acquired the data. P-LT, W-CH and J-SY analysed and interpreted the data and statistical analysis results. W-CH, S-HK and W-TH drafted the manuscript. G-YM and $\mathrm{H}-\mathrm{TC}$ performed critical revisions of the manuscript for important intellectual content. W-CH and C-PL supervised the study.

Funding This research received no specific grant from any funding agency in the public, commercial or not-for-profit sectors.

Competing interests None declared.

Patient consent Not required.

Ethics approval Human Research Committee of Kaohsiung Veterans General Hospital, Taiwan.

Provenance and peer review Not commissioned; externally peer reviewed. Data sharing statement No additional data are available.

Open Access This is an Open Access article distributed in accordance with the Creative Commons Attribution Non Commercial (CC BY-NC 4.0) license, which permits others to distribute, remix, adapt, build upon this work non-commercially, and license their derivative works on different terms, provided the original work is properly cited and the use is non-commercial. See: http://creativecommons.org/ licenses/by-nc/4.0/

C Article author(s) (or their employer(s) unless otherwise stated in the text of the article) 2018. All rights reserved. No commercial use is permitted unless otherwise expressly granted.

\section{REFERENCES}

1. Wong CP, Loh SY, Loh KK, et al. Acute myocardial infarction: Clinical features and outcomes in young adults in Singapore. World $\mathrm{J}$ Cardiol 2012;4:206-10.

2. White HD, Chew DP. Acute myocardial infarction. Lancet 2008;372:570-84.

3. Silvain J, Collet JP, Nagaswami C, et al. Composition of coronary thrombus in acute myocardial infarction. J Am Coll Cardiol 2011;57:1359-67.

4. Huang WC, Chiou KR, Liu CP, et al. Multidetector row computed tomography can identify and characterize the occlusive culprit lesions in patients early (within 24 hours) after acute myocardial infarction. Am Heart J 2007;154:914-22.

5. Liu CP, Lin YH, Lin MS, et al. Evaluation of myocardial infarction patients after coronary revasculation by dual-phase multi-detector computed tomography: Now and in future. World $\mathrm{J}$ Cardiol 2013;5:115-8.

6. Huang WC, Liu CP, Wu MT, et al. Comparing culprit lesions in STsegment elevation and non-ST-segment elevation acute coronary syndrome with 64-slice multidetector computed tomography. Eur J Radiol 2010;73:74-81.

7. Huang WC, Wu MT, Chiou KR, et al. Assessing culprit lesions and active complex lesions in patients with early acute myocardial infarction by multidetector computed tomography. Circ $J$ 2008;72:1806-13.

8. Nieto FJ. Infections and atherosclerosis: new clues from an old hypothesis? Am J Epidemiol 1998;148:937-48.

9. Arcari CM, Nelson KE, Netski DM, et al. No association between hepatitis $\mathrm{C}$ virus seropositivity and acute myocardial infarction. Clin Infect Dis 2006;43:e53-6.

10. Ishizaka N, Ishizaka Y, Takahashi E, et al. Association between hepatitis $\mathrm{C}$ virus seropositivity, carotid-artery plaque, and intimamedia thickening. Lancet 2002;359:133-5.

11. Oliveira CP, Kappel CR, Siqueira ER, et al. Effects of hepatitis $C$ virus on cardiovascular risk in infected patients: a comparative study. Int $J$ Cardiol 2013;164:221-6.

12. Alter MJ. Epidemiology of hepatitis $C$ in the West. Semin Liver Dis 1995;15:5-14.

13. Barone M, Viggiani MT, Amoruso A, et al. Endothelial dysfunction correlates with liver fibrosis in chronic HCV infection. Gastroenterol Res Pract 2015;2015:1-7.
14. Fukui M, Kitagawa $\mathrm{Y}$, Nakamura N, et al. Hepatitis $\mathrm{C}$ virus and atherosclerosis in patients with type 2 diabetes. JAMA 2003;289:1245-a-6.

15. Adinolfi LE, Restivo L, Zampino R, et al. Chronic HCV infection is a risk of atherosclerosis. Role of HCV and HCV-related steatosis. Atherosclerosis 2012;221:496-502.

16. Targher G, Bertolini L, Padovani R, et al. Differences and similarities in early atherosclerosis between patients with nonalcoholic steatohepatitis and chronic hepatitis B and C. J Hepatol 2007;46:1126-32.

17. Butt AA, Xiaoqiang W, Budoff $M$, et al. Hepatitis $C$ virus infection and the risk of coronary disease. Clin Infect Dis 2009;49:225-32.

18. Vassalle $\mathrm{C}$, Masini S, Bianchi F, et al. Evidence for association between hepatitis $C$ virus seropositivity and coronary artery disease. Heart 2004;90:565-6.

19. Tsai MS, Hsu YC, Yu PC, et al. Long-term risk of acute coronary syndrome in hepatitis $C$ virus infected patients without antiviral treatment: A cohort study from an endemic area. Int $J$ Cardiol 2015;181:27-9.

20. Huang $\mathrm{H}$, Kang $\mathrm{R}$, Zhao $\mathrm{Z}$. Is hepatitis $\mathrm{C}$ associated with atherosclerotic burden? A systematic review and meta-analysis. PLoS One 2014;9:e106376.

21 He Huang, Kang R, Zhao Z. Hepatitis $C$ virus infection and risk of stroke: a systematic review and meta-analysis. PLoS One 2013;8:e81305.

22. Adinolfi LE, Restivo L, Guerrera B, et al. Chronic HCV infection is a risk factor of ischemic stroke. Atherosclerosis 2013;231:22-6.

23. Wang $\mathrm{CC}, \mathrm{KaO} \mathrm{JH}$. Hepatitis $\mathrm{C}$ virus infection, lipids, and coronary heart disease: a Pandora's box. Hepatology 2010;51:343-4.

24. Petta S, Macaluso FS, Craxì A. Cardiovascular diseases and HCV infection: a simple association or more? Gut 2014;63:369-75.

25. Mostafa A, Mohamed MK, Saeed M, et al. Hepatitis C infection and clearance: impact on atherosclerosis and cardiometabolic risk factors. Gut 2010;59:1135-40.

26. Wong RJ, Kanwal F, Younossi ZM, et al. Hepatitis C virus infection and coronary artery disease risk: a systematic review of the literature. Dig Dis Sci 2014;59:1586-93.

27. Roed T, Lebech AM, Kjaer A, et al. Hepatitis $C$ virus infection and risk of coronary artery disease: a systematic review of the literature. Clin Physiol Funct Imaging 2012;32:421-30.

28. Ishizaka N, Ishizaka Y, Takahashi E, et al. Increased prevalence of carotid atherosclerosis in hepatitis B virus carriers. Circulation 2002;105:1028-30.

29. Pothineni NV, Delongchamp R, Vallurupalli S, et al. Impact of hepatitis $C$ seropositivity on the risk of coronary heart disease events. Am J Cardiol 2014;114:1841-5.

30. Momiyama Y, Ohmori R, Kato R, et al. Lack of any association between persistent hepatitis $B$ or $C$ virus infection and coronary artery disease. Atherosclerosis 2005;181:211-3.

31. Kiechl S, Egger G, Mayr M, et al. Chronic infections and the risk of carotid atherosclerosis: prospective results from a large population study. Circulation 2001;103:1064-70.

32. Forde KA, Haynes K, Troxel AB, et al. Risk of myocardial infarction associated with chronic hepatitis $C$ virus infection: a populationbased cohort study. J Viral Hepat 2012;19:271-7.

33. Metwally $A H$, Elgamal MA. The relation between hepatitis $C$ virus and coronary heart disease. Med Hypotheses 2014;82:505.

34. Pothineni NV, Rochlani Y, Vallurupalli S, et al. Comparison of angiographic burden of coronary artery disease in patients with versus without hepatitis $\mathrm{C}$ infection. Am J Cardiol 2015;116:1041-4.

35. Cheng CL, Lee $\mathrm{CH}$, Chen PS, et al. Validation of acute myocardial infarction cases in the national health insurance research database in Taiwan. J Epidemiol 2014;24:500-7.

36. Chiang $\mathrm{CH}$, Huang WC, Yang JS, et al. Five-year outcomes after acute myocardial infarction in patients with and without diabetes mellitus in Taiwan, 1996-2005. Acta Cardiol Sin 2013;29:387-94.

37. Sun LM, Lin MC, Lin CL, et al. Statin use reduces prostate cancer all-cause mortality: a nationwide population-based cohort study. Medicine 2015;94:e1644.

38. Wang JY, Wang CY, Tan $\mathrm{CH}$, et al. Effect of different antipsychotic drugs on short-term mortality in stroke patients. Medicine 2014;93:e170.

39. Kuo PL, Lin KC, Tang PL, et al. Contribution of hepatitis B to longterm outcome among patients with acute myocardial infarction: a nationwide study. Medicine 2016;95:e2678.

40. Ishizaka N, Ishizaka Y, Yamkado M. Atherosclerosis as a possible extrahepatic manifestation of chronic hepatitis $\mathrm{C}$ virus infection. Clin Med Insights Cardiol 2014;8:CMC.S17069-5.

41. Abougergi MS, Karagozian R, Grace ND, et al. ST elevation myocardial infarction mortality among patients with liver cirrhosis: 
a nationwide analysis across a decade. $J$ Clin Gastroenterol 2015:49:778-83.

42. Allman KC, Shaw LJ, Hachamovitch R, et al. Myocardial viability testing and impact of revascularization on prognosis in patients with coronary artery disease and left ventricular dysfunction: a metaanalysis. J Am Coll Cardiol 2002;39:1151-8.

43. Antithrombotic Trialists' Collaboration. Collaborative meta-analysis of randomised trials of antiplatelet therapy for prevention of death, myocardial infarction, and stroke in high risk patients. BMJ 2002;324:71-86.

44. Pitt B, White H, Nicolau J, et al. Eplerenone reduces mortality 30 days after randomization following acute myocardial infarction in patients with left ventricular systolic dysfunction and heart failure. $J$ Am Coll Cardiol 2005;46:425-31.

45. Marui A, Kimura T, Tanaka S, et al. Coronary revascularization in patients with liver cirrhosis. Ann Thorac Surg 2011;91:1393-9.

46. Singh V, Patel NJ, Rodriguez AP, et al. Percutaneous coronary intervention in patients with end-stage liver disease. Am J Cardiol 2016;117:1729-34.

47. Nilsson E, Anderson H, Sargenti K, et al. Incidence, clinical presentation and mortality of liver cirrhosis in Southern Sweden: a 10-year population-based study. Aliment Pharmacol Ther 2016:43:1330-9.

48. CDC. Centers for Disease Control. Viral hepatitis surveillanceUnited States. 2013 http://www.cdc.gov/hepatitis/statistics/2013surv eillance/pdfs/2013hepsurveillancerpt.pdf (accessed 3 May 16).
49. Innes $\mathrm{H}$, Hutchinson $\mathrm{SJ}$, Obel $\mathrm{N}$, et al. Liver mortality attributable to chronic hepatitis C virus infection in Denmark and Scotland--using spontaneous resolvers as the benchmark comparator. Hepatology 2016:63:1506-16.

50. Grebely J, Page K, Sacks-Davis R, et al. The effects of female sex, viral genotype, and IL28B genotype on spontaneous clearance of acute hepatitis C virus infection. Hepatology 2014;59:109-20.

51. Siagris D, Christofidou M, Theocharis GJ, et al. Serum lipid pattern in chronic hepatitis C: histological and virological correlations. J Viral Hepat 2006;13:56-61.

52. Corey KE, Kane E, Munroe C, et al. Hepatitis C virus infection and its clearance alter circulating lipids: implications for long-term follow-up. Hepatology 2009;50:1030-7.

53. Marzouk D, Sass J, Bakr I, et al. Metabolic and cardiovascular risk profiles and hepatitis $C$ virus infection in rural Egypt. Gut 2007;56:1105-10.

54. Shepard CW, Finelli L, Alter MJ. Global epidemiology of hepatitis C virus infection. Lancet Infect Dis 2005;5:558-67.

55. Mohd Hanafiah K, Groeger J, Flaxman AD, et al. Global epidemiology of hepatitis $C$ virus infection: new estimates of age-specific antibody to HCV seroprevalence. Hepatology 2013;57:1333-42.

56. Chen YC, Lin HY, Li CY, et al. A nationwide cohort study suggests that hepatitis $C$ virus infection is associated with increased risk of chronic kidney disease. Kidney Int 2014;85:1200-7. 